\title{
Necessarily Free: Why Teachers Must be Free
}

\author{
Orit Schwarz-Franco' ${ }^{1}$ iD
}

Accepted: 22 November 2021 / Published online: 1 December 2021

(C) The Author(s), under exclusive licence to Springer Nature B.V. 2021

\begin{abstract}
Teachers are necessarily free. The present article discusses the dual meaning of this necessity. The first meaning relates to freedom as an inevitable aspect of the actual reality in the classroom (the "is"); the second to teachers' freedom as the ideal condition, or a prerequisite for optimal teaching (the "ought"). Existentialist philosopher Jean-Paul Sartre argued that human beings are "condemned to be free" and demanded that freedom be considered an imperative value. Philosopher of education Joseph Schwab, who analysed the practical nature of teaching, concluded that teachers make choices every minute in the classroom, and demanded that their autonomy be expanded. This article identifies parallels between these two philosophical moves and suggests complementing features. Sartre adds universal depth to Schwab's portrait of teachers, proving them to be an extreme expression of the human condition. Schwab provides Sartre's analysis with concrete validation and practical suggestions for implementation. Combining these two approaches can further establish the importance of teacher autonomy and offer a unique conceptualisation of teacher agency as a partial response to the crisis of education in the postmodern era.
\end{abstract}

Keywords Joseph Schwab · Jean-Paul Sartre - Teachers' autonomy · Lived curriculum · Freedom

\section{Introduction}

Freedom is an essential necessity for teachers. This statement encapsulates two notionsthat of the reality in the classroom (the "is") and the ideal situation (the "ought"). The first observation is that teacher freedom or autonomy is inevitable. It is a fact: freedom is a given, and no administrator or committee can deny teachers of it. The second argument is that this freedom is a normative imperative. Under this approach, freedom must be a prerequisite for education: teacher autonomy is appropriate and worthwhile and must be preserved and

Dr. Orit Schwarz-Franco Ph.D

orit.shfranco@gmail.com

1 Beit-Berl Academic College, Beit Berl, Israel 
expanded. Granted, at first glance the first argument seems to make the second redundant: if freedom exists by definition, why do we need to ensure it?

Existentialist philosopher Jean-Paul Sartre (1905-1980) characterizes the meaning of life and human existence as follows: the individual has absolute freedom, by the mere fact of being a sentient subject. In "Existentialism is a Humanism" (Sartre, 2007/1946), he recommends that we all respect our own and others' freedom, and even calls for recognizing freedom as an imperative value.

American professor of education Joseph Schwab (1909-1988) studied curricula. In a series of articles called "The Practical" (Schwab 1969, 1971, 1973, 1983), he argues that teachers enjoy considerable freedom of action, derived from the nature of teaching as a practical art. He also recommends that teachers be given autonomy in their work and be involved in curricular decision making.

Thus, the duality presented above - of freedom as a given fact and freedom as a value to strive towards - emerges in the works of both scholars. In what follows, I attempt to resolve the tension arising from this duality, which appears to make the normative argument redundant, and show how the two are not contradictory but rather mutually enriching. I suggest that Sartre and Schwab's approaches are mutually inspirational, so that reading them together may offer complement aspects lacking in each. Sartre's conceptualization provides Schwab's observations with existential universal depth, whereas Schwab's discussion of teachers provides Sartre's doctrine with revalidation and suggestions for concrete implementation.

The analogy between the two arguments may seem surprising, as the two thinkers come from very different schools of thought; namely, French existentialism (continental philosophy) and American pragmatism. Indeed, at some points in the discussion below these differences clearly emerge. However, I suggest that eventually, when coming to acknowledge the individual's daily challenge, their legacies converge.

Taken jointly, the two notions imply that the work of a teacher within a classroom is a particular case of the individual's task within human existence. Moreover, teachers' unique role both expands their freedom and magnifies their responsibility, thereby contributing to their existential challenge. Finally, combining Sartre's and Schwab's ideas can provide strong justification for teachers' autonomy, and refine the meaning of teachers' agency as a partial response to the cultural and ethical crisis of education in the postmodern era.

In the next three sections I inquire three conceptions of freedom: as destiny, as an imperative value, and as a solution to a crisis. In each section I begin with Sartre, reading him selectively and stressing ideas that would serve me later for existential reading of Schwab. then I present Schwab's perspective, and offer a comparative synthesis between the two thinkers. The fourth and last section of the paper goes beyond the theoretical synthesis, onto pedagogical implications for the classroom and school.

\section{Freedom as Destiny}

\section{Sartre: "Man is Condemned to be Free"}

Sartre understands Nietzsche's news of the death of God as a characterization of human existence. He discusses clearly the direct result of the absence of the divine: "Atheistic exis- 
tentialism, which I represent [...] states that if God does not exist there is at least one being in whom existence comes before its essence [...]. That being is man" (Sartre, 2007/1946, 22). In the absence of a Creator who designs human character and predetermines its essence, individuals remain devoid of essence, indeterminate, until they come to exist, live and act, and define themselves through their actions.

The only definition that applies to the individual a priori is that of being free. As sentient beings, humans are not objects manipulated by external forces that make choices for them; rather, they are subjects who choose their action at any given moment and in turn are shaped by these choices. Accordingly, individuals are absolutely responsible for their actions and their being. Sartre (2007/1946) accepts no excuse, no shirking of responsibility; Circumstances and conditions affect human choices, but they never determine them. It is up to the individual to choose how to interpret these conditions and cope with the circumstanceswhether to act under their influence or revolt against them. Even attempts to eschew one's freedom by 'handing it' to other individuals or organizations with authority - by obeying the law, the priest or the military commander-do not relieve one of the burden of freedom. Even the person who obeys another interprets the order as a given and chooses whether to comply.

This analysis of choice highlights the loneliness of the individual. Sartre also describes an experience of "abandonment" (p. 25) accompanied by the anxiety necessarily involved in recognizing one's freedom. Both loneliness and abandonment stem from the absence of God and the fact that no other being can replace Him as the human individual's guide or mentor.

The need to choose, argues Sartre, is structured into the third of only three conditions imposed on all of us without our choosing, and which therefore constitute the human condition: birth, death, and action. $(2007 / 1946,42)$ The first two merely frame our existence; therefore, it is the third that is of particular interest. From the moment of our birth, and each morning anew, we have no choice but to act upon our choices. Even the choice not to act, to "do nothing," is a choice of action, which may be particularly significant when we choose to ignore an injustice, for example. According to Sartre, our responsibility for inaction is just as great as our responsibility for action.

Beyond absolute individual responsibility, Sartre imposes a general responsibility on every human being: "Our responsibility is thus much greater than we might have supposed, because it concerns all mankind" (2007/1946, 24). This can have three meanings. The first is that as social creatures, all people socialize with others, and in every public act affect all those who witness their action. Second meaning is that in the absence of general human nature, humanity remains faceless, a mere mosaic of individual faces. It has no vision, no grand narrative. Humanity's story is written at every moment by the choices individuals make; they are each the sums of their actions, and humanity is the grand total of the sums of all actions. The third meaning relates to the fundamental philosophical assumptions of existentialism: without an omniscient God who provides objective validity to moral values, humans' choice is the only element that can provide general value to their every action. Only my choice determines what is good, and it is always, by definition, a general choice - by acting I take a stand.

With regard to literature in particular, Sartre (1949/1947) clarified that spoken words also constitute actions, which shape the human world. The only truth we as subjects can access is our private interpretation of reality, and therefore our overall truth is the sum of individual interpretations. When one speaks or writes, one must take as much responsibility as one 
would take when firing a pistol. Writers who publish must take double responsibility and assume that all humanity will read and be affected by their words. Indeed, a writer's choice to remain silent about injustice is also fateful, just as it is in the case of inaction mentioned above.

Sartre would have probably seen a heightened application of his concept of general responsibility in the recent globalization processes, particularly in the use of information technology. Additionally, the COVID-19 pandemic has given us another opportunity to reflect on the meaning of personal and general responsibility. Each one of us chooses how to deal with the endless amounts of information on the disease, deciding whom to believe and how to act at home and in public. All these individual choices had an exponential effect on other people's health, as well as on their own choices in this regard. To note two poignant examples, a few Italians singing opera on their balconies started a global wave of distinct cultural creativity, while teachers and lectures who began teaching online reinterpreted the relationship between learning and the physical settings in which it takes place.

\section{Schwab: The Teacher is Condemned to Freedom}

Schwab's claim that teachers' freedom is inevitable can be seen as a particular case of Sartre's generalization about humankind. Indeed, the context of their discussion is different: Sartre expands his gaze to the metaphysical sphere and to the universal human society, whereas Schwab focuses on the setting of one classroom. However, he presents the teacher as a special case of a person who must cope with both existential challenges that face any other person and the professional ones facing teachers.

Sartre did not elaborate on this particular challenge, but as we saw above, he did consider certain professions to necessitate an elevated degree of responsibility. We can argue that just as the writer maintains special responsibility for the potential effect of her writing on its readers, so does every teacher bear extended responsibility for her teachings' direct effect on the students. However, Schwab (1983) does not settle for such deduction, making a unique claim regarding teachers' freedom, derived from the very nature of their work: "Teachers will not and cannot be merely told what to do[...] Teachers are not assembly line operators, and will not so behave" (p. 245).

This bold statement suggests that for Schwab this is neither a recommendation nor wishful thinking, but simply a description of reality. Just as Sartre derives the necessity of human choice from the description of human existence, so does Schwab derive the necessity of teachers' freedom from the nature of teaching as a "practical art."

Let us first dwell on the adjective "practical." In Practical 1, Schwab (1969) addresses what he considers to be a curricular crisis. The reason for that crisis, he argues, is that planning learning is a distinctly practical area, whereas the authorities in charge approach it from a theoretical perspective, trying to reform the learning based on particular theories. To explicate this idea, Schwab devoted much of the article to differentiating between theory and practice. He argued that the gap between the two was essential and unbridgeable.

Beyond this difference, which applies to all theories, Schwab identifies another limitation, unique to theories in the social sciences, which particularly affect curricula. The problem in aligning such theories with practice, he argues, is that they deal with the most complex of research objects: humankind. Schwab argues that each of the social sciences observes the complexity of humanity from only one perspective, and that each theory exam- 
ines its object of inquiry from a single standpoint. Therefore, relying on only one theory necessarily involves missing out on multiple potential perspectives and ignoring multiple aspects of humanity.

The overarching argument that a curriculum must never be considered absent direct engagement with its context - concrete practice in the classroom and schools-accompanies Schwab's writings throughout his career. In their comprehensive review of Schwab's lifelong contribution to the curricular area, Craig and Ben-Peretz (2018) emphasize his call on educators to avoid "flights from the field" (Schwab 1969) and shift their gaze from wellordered theories to the chaotic classroom scene: "The preface to Schwab's Community: A mission for the Schools, most closely aligns with Schwab's enduring defence of "The Practical'"' (Craig and Ben-Peretz 2018, 430).

Obviously, curricular planning cannot be boxed into a theory, since no teacher can focus her work in the classroom on a single aspect of their work and examine it from a single point of view. The teaching act always addresses concrete situations, ${ }^{1}$ each involving a complex entanglement of inseparable aspects: the human mind and body, the social environment, and other aspects are always intermingled, each integral to its complexity. The exceptionally long and unusually punctuated definition Schwab (1983) proposes for "curriculum" attests to both its concreteness and its complexity:

Curriculum is what is successfully conveyed to differing degrees to different students, by committed teachers using appropriate materials and actions, of legitimated bodies of knowledge, skill, taste, and propensity to act and react, which are chosen for instruction after serious reflection and communal decision by representatives of those involved in the teaching of a specified group of students who are known to the decision makers. (p. 240)

Schwab further emphasizes that educating is always about something concrete. Every literature lesson deals with a specific text and is delivered by a specific teacher to specific group of students. The text, the teacher and students have unique characteristics, as do circumstantial details of the time, place and setting of the lesson. Most of these characteristics will be ignored by any theory on teaching literature but would be decisive to the teaching act itself. Below, we will illustrate how these details affect teachers' decisions in the classroom; but before that, we must turn our attention to the second term in the phrase "practical art."

Why does Schwab (1983) characterize teaching as art? He explains that the gap between every theory and the concrete teaching act turns teaching into activity that requires constant creativity, which cannot be subject to general rules or directed by predetermined guidelines. Such activity, Schwab argues, is art. It is interesting to inquire as to whether he means fine art such as composition, painting, or sculpture, or rather performance art, such as playing music, singing or dancing. In the latter, the audience is exposed to the art each time anew, each time in a unique and inimitable form, with the element of creativity including not only the original composition or choreography, but the performance itself, particularly if it involves interaction with the audience. Schwab does not refer to this distinction, but I believe his characterization of teaching as an art is particularly applicable to the performance arts, given their dynamic and singular nature. As such, teaching involves an even

\footnotetext{
${ }^{1}$ Here, Schwab is influenced by Dewey's (1966/1916) pragmatism, borrowing the concept of the "situation" as the context in which every thinking or learning act takes place. He is also inspired by the Aristotelian focus on practice and disapproval of idealism and theoreticism (Ben-Peretz and Craig 2018).
} 
greater degree of creativity than other arts, for two reason. First, having prepared the lesson plan, the teacher is usually the 'author' of the lesson. Second, preforming the lesson involves ongoing interaction with the student 'audience,' which is essential to teaching: a dancer can go on dancing even if the audience remains indifferent, whereas a teacher cannot teach in any meaningful sense if the students are not engaged.

Beyond characterizing teaching as a practical art, Schwab details several specific arts required to bridge the gap between theory and practice in teaching work. "Practical art" is the ability to apply theory to a specific case, and "eclectic art" requires the combination of several theories and working with them in parallel, while cognizant of the limitations of each. The gap between theory and practice essentially points to a gap between every curriculum or teaching guidelines and the concrete decisions made by a specific teacher at a given moment:

Teachers practice an art. Moments of choice of what to do, how to do it, with whom and at what pace, arise hundreds of times a school day, and arise differently every day and with every group of students. No command or instruction can be so formulated as to control that kind of artistic judgment and behaviour, with its demand for frequent, instant choices of ways to meet an ever varying situation. (Schwab 1983, 245)

This description suggests that one way in which teachers are condemned to freedom involves the particularly high number of decisions they must make: "they have no need, except in rare instances, to fall back on defiance as a way of not heeding. There are a thousand ingenious ways in which commands on what and how to teach can, will and must be modified or circumvented in the actual moments of teaching" (Schwab 1983, 246). Thus, in claiming the freedom of teachers, Schwab does not refer to rebellious or otherwise unique practitioners of the art of teaching: freedom is simply essential to any teaching.

The complexity of the interpretational, proactive, and critical role of teachers, is what made Schwab name it "an impossible role". He stresses that “... It is not even enough to possess organized knowledge of ways and means. This is to interpret a policy and tend to its efficient execution but not to be able to improve a policy or change it as problems change..." $(1959,159)$.

Other scholars have also highlighted freedom of choice as critical to Schwab's notion of the teacher's work. Westbury $(2005,94)$ claims that "Schwab made the case for an alternative starting point built around the forms of thought that address choice and action in the reality of ongoing experience." Still others, such as curriculum scholar Ted Aoki, recognized Schwab's profound influence on the way curricula and lesson plans are being conceived, and emphasized the dynamic values and awareness of the necessary and obvious gap between theoretical planning on the one hand, and the 'lived curriculum'-i.e., live performance in class on the other:

Curriculum making, a term introduced by Joseph Schwab, reflects the dynamic process of learning in which the teacher, learner, subject matter, and milieu interact [...]. Aoki's understanding of curriculum-as-plan and lived curriculum $[\ldots$ is $]$ that the lived experience of curriculum in schools is much more complex and varied than the planned curriculum that is meant for a generalized audience. (Hutchinson and Clarke 2019, 17) 
To illustrate the inability of guidelines to address each and every situation that takes place in class like factory rules can guide assembly line workers, let us take the example of a literature lesson on Dr Jekyll and Mr. Hyde. Suppose Ronna asks her teacher, "Well, everybody has a good side and a bad side, don't they? It's like when somebody sometimes beats his kids, but he also loves them, and he doesn't really mean it..." At that point, the teacher has to decide from a range of potential responses. She could ignore the question; give Ronna a straight answer; reflect the question back at her or at another student, using different words; or recall a question asked by another student in a previous lesson, also related to the violence in the novel. This does not exhaust the "classroom performer's" alternatives, however. She can refer the entire classroom directly to relevant passages in the text, or to an interpretive article about it, so that they find the answer themselves. She may also decide to defer the discussion to a more advanced stage in the study of that novel. More directly relevant to Ronna and as part of the teacher's broader role definition as an educator, it might be a good idea to have a private conversation with Ronna and/or report this conversation to the school counsellor.

Whatever the teacher decides, her decision will be based on multiple details, and on her unique ability to integrate them all and come up with a timely, practical solution, as the classroom scene unfolds. She may have privileged access to information about the novel; but more importantly, about the particular student, her classmates, the previous and the next lesson, and what may be going on in Ronna's home. Her concrete response can never be prewritten into the curriculum. She is alone in class and must make her own decisions. The classroom is full of noisy students, but just as for Sartre the individual is always alone in her choice and her responsibility, so is the teacher alone in her role as the responsible adult in the classroom. Just as for Sartre one who consults with others or obeys them remains responsible for one's decision, so does the teacher, even if she follows a predetermined curriculum, make her own choice in interpreting the curriculum or lesson plan in response to an emerging classroom situation.

The same notion can also be illustrated using a seemingly simpler example, involving how the teacher chooses to enforce school regulations. Suppose the school principal decided on a strict policy regarding tardiness, and disseminated a memo asking all teachers to send all students who are tardy directly to the principal's office. The time is eight and seven minutes, and our teacher has just begun her lesson - and Ronna is at the door. The teacher has to respond immediately. Should she ask why Ronna is late in front of the whole class? Send her straight to the principal's office? Let Ronna in with a reprimand and ask her to talk to her after the lesson? Let her in with a reprimand, but with a smile? Without neither? Given the audience and time pressure inherent to this performative situation, the teacher's decision will be necessarily spontaneous and uncalculated; yet it would necessarily rely on all she knows about Ronna-where she lives and with whom, who wakes her up in the morning and how she arrives to school, what medications she may be taking that affect her appetite and sleeping habits, whether she has to take her younger sister to preschool before coming to class. In making her instant decision, the teacher will also take into consideration what she knows about the rest of the class-how frequently other students are late, recent disciplinary incidents, and other issues. Additionally, consciously or not, she will also factor in her own personal background and character, her educational priorities, and the values to which she is committed at work - the education she received from her parents, and how she feels about it, her own tendency to punctuality or lack thereof, her ideas about the need for 
personal and empathetic attention to students or for strict boundary setting, her experience as a teacher and previous experiences with other students who may be coping with similar issues at home.

The detailed discussion of the two examples is designed to illustrate the rich complexity of factors and considerations entering into teachers' decisions at any given moment as they perform in class. These examples serve to justify Schwab's characterization of teaching as a practical art, thereby unfitting for any framework of rules or guidelines. The teacher constantly makes choices; she cannot avoid them; she is doomed to freedom.

It may be argued that the "lived curriculum" as "live performance in class" is no longer quite so dominant a learning mode since the pandemic; It is interesting to ask: does virtual schooling call into question Schwab's conception of teaching? In what ways does a prerecorded lecture, or one delivered during a Zoom class with students not visible, require instructional choices? This question deserves a separate discussion that exceeds the limits of this paper, so I will only share two initial thoughts on that point. On one hand, I say yes, a synchronic lesson delivered in Zoom is still a scene of living human beings, and it still carries the endless social and emotional complexity of a group of people, even though their bodies are not present in the same physical. Further, the Zoom scene includes additional details, as for the example the multiple private spaces shared through the cameras, and new kinds of dilemmas emerge, that were never met by teachers before, and require fresh considerations. On the other hand, as we know, Covid19 has brought into school-life also a-synchronic learning where interaction is reduced to minimum, where the teacher's role as portrayed here is hardly recognizable. On these aspects of current teaching and learning I say that the lack of lived interaction is exactly the reason why this is not a desirable routine for schools, and it must remain a partial temporal substitute and not a constant alternative to real life in school classes.

To conclude the first section, this integration of Sartre's and Schwab's insights on personal freedom and the curriculum provides two key insights on the teacher's classroom work. First, the teacher is a particular case of the human individual: the teacher is free, alone, and responsible in the classroom, just as every individual is free, alone, and responsible in the household, at work, or in the battlefield. Second, the teacher's burden of free choice is more intense and extreme than it is in many other pursuits, as the complexity, immediacy and consequences of the teacher's choices are multiplied exponentially given the immediate, live nature of the classroom drama.

In the next section, we discuss this freedom, again based on Sartre and Schwab, not in the terms of inevitable destiny, but rather in terms of a human value and a challenge, as individual choices often clash with social forces.

\section{Liberty as Value and a Challenge}

\section{Sartre: Freedom as a Human Commitment}

In "Existentialism is a Humanism," Sartre also offers a moral doctrine, based on the consequences of his characterization of the human situation. Following the concept that to be human is to be free, he posits liberty as a value and proposes that we respect our own and others' freedom: "when, operating on the level of complete authenticity, I have acknowl- 
edged that existence precedes essence, and that man is a free being [...] I have at the same time acknowledged that I must will the freedom of others." (Sartre, 2007/1946, 49). The requirement that we respect our freedom and that of others is reminiscent of the second formulation of Kant's categorical imperative, to act in such a way that you treat humanity never merely as a means to an end, but always as an end in itself. The reasoning is also similar; the fact that humans are sentient beings distinguishes them from objects and prevents us from treating them as such (Kant 1993/1785).

As we have seen above, Sartre suggests that philosophically, our own and others' freedom cannot be taken away from us, since it is necessarily given. Even if we bind a man in chains and throw him to the dungeon, we cannot deny his freedom of thought, which enables him to interpret his situation. In practice, however, in socio-political terms, realizing the freedom of everyone depends on the degree of freedom we relegate to others. If we live in a society that routinely denies the freedoms of others, eventually ours too will be denied.

In this context, we discover each time anew the necessity of the constant struggle to defend democracy, as a way of life committed to individual freedom. This aspect of Sartre's thought raises new insights and mainly new questions during the COVID-19 crisis. Have the severe restrictions placed on freedom of movement been morally justified? Can the government decide for the citizens that life and health take precedence over freedom? Most of us would probably agree to that normative prioritization, but many have criticized the manner in which certain governments took advantage of the crisis to increase surveillance and limit the freedom of citizens, and even use these limitations for political purposes.

Sartre refers to the recognition of freedom and responsibility as "authenticity," leading to respecting one's own freedom and that of others as a binding value. Sartre presents authenticity as an insight forced upon us on the basis of our recognition of the nature of human existence. It leads us by way of logical necessity to the conclusion that we must evaluate freedom, and it is based on what is given to us as human subjects.

Sartre clearly considers authenticity the preferable or appropriate human position, while deeming wrong its opposite: self-denial, or the denial of our own and others' freedom. Sartre insists that it is a dishonest, cowardly and inappropriate position, and expresses this view in no uncertain terms, as his own personal view, after his rejection of the possibility of valid universal values has left him unable to state as much objectively:

"what if I want to be in bad faith?" I would reply "There is no reason why you should not be, but I declare that you are, and that a strictly consistent attitude alone demonstrates good faith." [...] those who conceal from themselves this total freedom under the guise of solemnity or by making determinist excuses I will call cowards. Others, who try to prove that their existence is necessary, when man's appearance on earth is merely contingent I will call bastards. But whether cowards or bastards, they can judged only on the ground of strict authenticity. (Sartre, 2007/1946, 49)

Note that the concept of authenticity provides a solution for the tension presented at the beginning of this article between the descriptive theory ("man is free") and the moral imperative ("freedom is to be respected"). As you may recall, we asked why freedom needs to be established as an imperative when its existence is given. Well, Sartre clarifies that although it is a fact that individuals are free in any case, many choose to deny that freedom and compromise their own and others' freedom. Freedom is a given, but its realization cannot be taken for granted. The authenticity criterion enables us to distinguish between people 
who apply their judgment to handle their freedom bravely and those who shirk it out of cowardice.

Sartre also proposes an explanation for the unfortunately common choice of denying freedom; namely, anxiety, anguish or nausea - that difficult sensation arising when we face the meaning of our being subjects. Other scholars, including Fromm (1941), have also identified the human fear of coping with freedom and the desire to avoid this coping. According to Sartre, people can flee freedom for self-denial in two ways: by denying freedom or denying responsibility. The deniers of freedom claim that they are subject to deterministic forces, which explain their choices as necessarily deriving from social, psychological, biological, or other constraints. The deniers of responsibility, on the other hand, attribute total individuality to their choice and claim it has no universal meaning and no impact on others.

Apart from individuals' self-denial, we also encounter the denial of freedom as a social and political phenomenon: social norms and regimes ignore the rights of individuals or groups to freedom and constrain people's possibilities for full expression and realization of that freedom. Therefore, the call to recognize freedom and respect it as a value is necessary; its aim is to empower individuals to utilize their inherent freedom and act, knowing that they are entitled to be free. Moreover, society must assure freedom as a value to enable complete realization of that freedom and promote a social life in keeping with the nature of human existence. As such, both individuals and society are called upon to cope with the challenge of freedom.

\section{Schwab: Autonomy for Teachers as a Goal and Challenge}

Just as Sartre moves from the reality to the desirable vision of it - from the "is" to the "ought" - so does Schwab move form claiming that teachers are condemned to freedom to calling for greater autonomy in the teachers' work, and for more significant involvement on their part in curricular decision making:

[...] teachers must be involved in debate, deliberation, and decision about what and how to teach. Such involvement constitutes the only language in which knowledge adequate to an art can arise. Without such a language, teachers not only feel decisions as impositions, they find that intelligence cannot traverse the gap between the generalities of merely expounding instructions and the practicalities of the teaching moment. $(1983,245)$

Here, the message is formulated as a recommendation for what education should look like, and we also have a double reasoning for the requirement to grant teachers autonomy. First, based on his characterization of teaching as a practical art, Schwab determines that the knowledge required for decision making is practical, available to those engaged in the practicalities of teaching. Subsequently in his discussion, he compares education to other practical disciplines related to human beings, such as government, economics, medicine, psychology, and law. He finds consensus already emerged in all these areas that theoretical knowledge is a problematic and partial source-hence the greater tendency to rely on knowledge accumulated by practitioners, such as legal precedents and clinical therapeutic experiences (Schwab 1969).

Second, Schwab argues that the teachers themselves sense the incompatibility between the nature of their work and attempts by various stakeholders and authorities to enforce 
guidelines upon them and otherwise interfere in their work. As discussed above, the teacher is aware that even if she wants to comply with the instructions of her supervisors, she would nevertheless have to interpret them herself, so that at the end of the day she would be making her own decisions and would be responsible for them.

Accordingly, the recognition of freedom and responsibility and their conscious realization by the teacher correspond with Sartre's authentic condition. As opposed to that, when teachers are not involved in deciding on these instructions, an inner tension is created. I propose to identify this tension with the self-denial Sartre describes; only this self-denial is forced upon teachers by their workplace conditions. Of course, this is an essential difference in the meaning of self-denial; Sartre recognises a psychological tendency, which characterises the subjective interpretation a person gives to her existential situation, whereas Schwab, following the pragmatistic tradition, points at a contextual-practical situation in which the person must make her choices. However, as mentioned above, Sartre also points at the denial of freedom as a social and political phenomenon, and in this regard, I recognise a greater relevance to Schwab's argument.

Note that unlike Sartre's difficulty to commit to an objective reasoning for preferring authenticity over self-denial, Schwab does manage to establish that preference pragmatically. As mentioned, in teachers' daily work they encounter countless situations of choice and responsibility. The quote above makes it clear that when systems try to restrict that freedom, the result is inconsistency or constant friction between the demands imposed on them and the essential nature of the practice. Accordingly, Schwab argues that the tension teachers face could be reduced if teachers are involved in making the decisions they are required to implement. This approach would ensure compatibility between the teacher's need to choose and ability to influence. Moreover, it would reduce the inner contradiction between the content of universal instructions and the concrete decisions individual teachers make in the classroom.

Therefore, Schwab's pragmatic suggestion concerning teacher's autonomy offers a partial solution, a comforting path, in the challenging journey away from the self-denial that Sartre has recognised as the general human condition.

This demand that teachers' agency be respected has accompanied Schwab throughout his career. Already in 1950, he debated a certain professor and defended the concept of teachers' peer learning, arguing that through such engagements their practical knowledge is appreciated as a precious source of professional development. (Ben-Peretz \& Craig, 2018). In another early example, while explaining Dewey's legacy, Schwab describes deliberation as a necessary condition for good teaching: "Only as the teacher uses the classroom as the occasion and the means to reflect upon education as a whole (ends as well as means), as the laboratory in which to translate reflections into actions and thus to test reflections, actions, and outcomes against many criteria, is he a good "progressive" teacher. (1959, 159). Even though freedom is not explicitly mentioned here, I suggest that such deliberative teaching can be fulfilled only in an environment that allows teachers professional liberty. Finally, in one of his late phrasings, teachers had to be treated as "agents of education" $(1987,128)$. Indeed, Agency may be the appropriate term to use nowadays, as Freedom is considered by some as irrelevant modernistic notion in a postmodern world. The post-modern setting to this discussion will be further elaborated below.

The comparison to Sartre again suggests an interesting insight. The teacher's work may be viewed as a problematic encounter between human existence, necessarily free, and a 
social and professional world that does not accept the existentialist characterization of human life and seeks to subject the individual teacher to strict rules and guidelines, with only supposed objective validity. The call to expand teachers' autonomy at work seeks to adjust the school to the true nature of human existence, and to that of the teacher's work in particular.

Now we must ask, how can we implement Schwab's recommendation to expand teachers' freedom? On the one hand, he does not support academic freedom for all teachers in their classrooms, since he prefers curricular decisions to be made on the basis of a broad overview of the various aspects encompassing the child's life and learning processes. Specifically, he defines four "commonplaces" that must be considered in every curricular discussion: the student, the teacher, the subject matter, and the environment (1973). On the other hand, he opposes the centralization of educational decision making. To ensure that educational decisions match the concrete local conditions of the students, teachers and community, he recommends a middle ground: decentralizing the decision-making processes to the school level. In particular, he proposes school curricular committees, and dwells on their optimal membership, to ensure that all "commonplaces" are properly represented and truly and successfully integrated.

When examining the suitable candidates for such a committee, first on Schwab's (1983) list are obviously the teachers. While arguably these are the obvious candidates, Schwab emphatically stresses this point. I believe he finds the need to do so because of the above-mentioned tension between the insight that teachers' freedom is essential and the understanding that both the systems that employ them and the teachers themselves underrecognize its importance. Schwab notes that of the four "commonplaces," teachers are the most neglected, arguing that they are underrepresented (if at all present) in curricular decision-making bodies.

Subsequently, Schwab proposes that teachers' involvement be required in making decisions about their work $(1983,245)$. The reasoning here is double: first, the teachers, who have the practical knowledge, are the relevant experts. Second, there is an additional positive consequence of involving teachers; namely, increasing their willingness to follow up on the decisions made, or in other words, their motivation at work. It is disappointing to realize, however, that Schwab's demand that teachers' influence in educational policy be expanded is still relevant nowadays, as an unfulfilled goal or as a call for a required change (Heineke et al. 2015).

Personally, I take inspiration from Schwab in arguing that greater autonomy breeds greater motivation - for everyone, and particularly for teachers. Extensive research evidence demonstrates this relationship overall between autonomy (e.g., Pink 2009), or selfdetermination (Deci and Ryan 2012), to motivation. When teachers are involved in deciding about their work, they work out of a sense of belonging and identification with the goals and processes decided on. Such an organizational structure provides teachers with ownership over their teaching processes and tap into completely different internal resources than those applied in working for external compensation only, or out of coercion. Conversely, when teachers' autonomy is reduced, they lose interest in their work and even abandon the field (Gates 2013).

It is interesting to 'stretch' our analogy between the general freedom of any human being (Sartre) and the specific freedom of teachers (Schwab), by looking at the final option of quitting. At first glance, it is a simple: a teacher can quit her job, just as a person can decide 
to 'quit life' by committing suicide. Thus, we might wonder, what is the existential value of this choice according to Sartre? Is it an authentic act? To my understanding, Sartre would not have accepted it as one. As mentioned above, dying is one of the three conditions that are not chosen, and which constitute the factual "Human Condition" (2007/1946, 42). We do not choose to be born, to act, and to die. Indeed, we can choose to bring death earlier, and pretend that we have control over death, whereas the reality is our complete lack of control. I suggest that authenticity includes not only the recognition of our freedom, but also the acknowledgement of its limitations. Therefore, quitting life is not an authentic choice, but rather a flight from the truth.

Additionally, as discussed above, our responsibility for non-action is just as great as for our positive choices. Choosing to die is naturally the most total non-action we can think of, bearing total responsibility for the non-being and non-action of our future absence for the people around us and for society as a whole.

Returning to Schwab's discussion with these insights in mind, we can see that an educator who acknowledges her responsibility for the education of the young generation realizes that quitting her job would not diminish her responsibility, but rather hold her even more responsible for neglecting her mission. Sartre helps us realize the depth and the size of the dilemma that a teacher faces when external forces deny her freedom, while internal sincerity prevents any flight from her responsibility.

To conclude, Schwab positions teacher autonomy as a value and a challenge for the decision-making bodies, just as Sartre positioned individual freedom as a challenge for societies and regimes. This position implies the need for concrete changes in educational policy to expand the freedom of choice offered to individual teachers at the various stages of their educational work. These implications are explored further in the last section below. Before that, I will explore the socio-philosophical status of the argument for freedom of choice, in it's historical context.

\section{Liberty as a Solution to a Crisis}

\section{Sartre: Individual Freedom as a Solution to a Moral Crisis}

When discussing freedom as given, as a value and as a challenge, Sartre (2007/1946) establishes the identification of existentialism with humanism, and thereby joins the humanist tradition according to which the human individual has moral standing by virtue of being a free subject, and which exalts human freedom as a supreme value.

To appreciate the full weight of Sartre's statements, we must consider their historical and cultural context. The lecture "Existentialism is a Humanism" was given in Paris in 1946. Needless to say, at the time France and the entire world were only beginning to cope with the tremendous moral crisis of the war and Holocaust. European culture, the Enlightenment, humanism, and the optimistic faith in progress for the entire human race - all these features have taken a severe and perhaps irreversible blow. This blow is generally considered to have put an end to modernism and marked the beginning of the postmodern era (Lyotard 2006; Natoli and Hutcheon 1993), who's most distinct cultural characteristic is moral relativism as widely adopted in Western society (Best and Kellner 2001). 
Sartre is no relativist, and in his lecture, he reacts to the onset of this major moral crisis and even responds directly to the critics of existential philosophy, who have considered it partly responsible for the loss of the moral path that took place during the Holocaust. Facing this crisis, he re-explains some of his ideas and derives normative conclusions from them, as we have seen. In his renewed call for humanism, and in emphasizing liberty as a binding value, it is as though he seeks to plant a tender seedling in earth that is grey and smoking after a huge fire.

Does he succeed? This question is highly debated. Some interpreters view his lecture as a philosophical "withdrawal" of sorts and consider it inconsistent with his previous thought (Golomb 1988). Such critics emphasize that given existentialism's own challenging of the ability to validate any objective values and following the cold shoulder Sartre had turned to any ideology in his earlier writings, his return to humanism or to any binding ethics cannot be accepted (Luria 2002). Others (myself included) consider this lecture an inspiring philosophical accomplishment, precisely given the thinker's willingness to develop his ideas and even change his mind, based on a sense of responsibility for the human and political reality of his time. In this respect, Sartre maintains consistency between the content of his words and his act of writing; he does so by talking about the human individual taking responsibility for all of humankind while doing so himself.

For me, Sartre's most important message here is that despite scepticism, we as mindful beings have no choice but to make a conscious choice, to take a stand at every given moment. Even if our judgement is not objectively universally binding, our decisions are subjectively universal ( i.e.each person judges from her personal point of view, but the judgement's content is general by nature), and therefore the values that guide them are important, and we must accept conscious responsibility for our normative choices and their implications. Moreover, the fact that we are subjects - sentient and free-makes us more valuable than objects, thereby renewing the validity of a single binding value, that of humanity, thus revalidating humanism.

\section{Schwab: Autonomy for Teachers as a Response to the Crisis in Education}

In this subsection, I discuss another aspect regarding which Sartre's characterization of freedom and Schwab's emphasis on teachers' autonomy share important parallels. Schwab, whose focus is on the teaching of science, shares with existentialism a complex, albeit not completely relativist view of knowledge. For example, in proposing a curriculum for teacher training institutes, Schwab $(1971,532)$ suggested a curriculum for teacher education programs that offers a "polyfocal" lesson plan; namely, one that combines multiple perspectives on the learning material - in this case, theories in social sciences. As part of the discussion on "eclectic art," he emphasizes that it is important for prospective teachers to learn several theories rather than settle for one. Moreover, their learning must be accompanied constantly by developing the students' reflective awareness of the nature of knowledge. The main purpose of the proposed curriculum is to walk the student teachers through the process of "transforming the doctrine into a view, moving it from the status of 'knowledge' toward being one mode of discriminating certain kinds of problems...." (Schwab 1971, 532) - the process whereby learners acquire the insight that every theory is an expression of a partial point of view affected by the researchers' presuppositions, values and interests. 
In this regard, Schwab (1971) returns to the characteristics of scientific theories presented above to derive insights on the kind of knowledge and the type of truth that may be found in them. As we have seen, the Practical series was written in the $1970 \mathrm{~s}$, some thirty years after Sartre's lecture and after Kuhn (1962) persuasively described the political and historical characteristics of scientific theories. Indeed, this was a time when the subjectivity of knowledge became widely accepted in general Western culture, beyond the narrow circles of philosophy. Following these insights, Schwab (1969) argues that research in social sciences and education must become more concrete and engaged with the field. In doing so, Schwab may have foreshadowed the qualitative turn in the study of education (e.g., Eisner 1981; Guba 1990;).

Moreover, qualitative research brings the researcher's role closer to that of the teacher. Indeed, several commenters have discussed Schwab's influence on qualitative research, as well as the emerging genre of self-study in particular, to the point of arguing that teachers' self-study should be considered a fifth "commonplace" of the curriculum and criticized the self-research community for not recognizing Schwab's decisive influence on their methodology. For example, Clarke and Erickson $(2004,203)$ claim that "there has been something of a collective amnesia in the self-study literature with respect to the foundational role played by Schwab."

Schwab's conceptualisation of knowledge may help us understand how thinkers from supposedly different schools of philosophy arrive at similar truths concerning the individual's daily challenge. In this sense, we can recall that despite the many clear differences between existentialism and pragmatism, the two share the negation of idealistic entities and absolute truths and seek out an earthly philosophy that stays limited to the human subjective experience in the world.

These shifts in the conceptualization of scientific knowledge have direct bearing on the status of education. Many have already highlighted the profound crisis of education in the postmodern era (e.g., Bloom 1987; Giroux 1993; Aviram 2010). In my view, we can identify in Schwab's characterization of teaching a potential solution for this crisis. If we accept the inquisitive, interpretive, and autonomous nature of the teachers' role, we can find a new basis for justifying their work even in an era of uncertainty. Just as Sartre made us realize that even if our values are not absolutely valid, we must still interpret reality and take a stand according to our understanding of it, and we must do so courageously and sincerely, Schwab made us realize that even if the curriculum or the values conveyed in class may not be considered 'objective truth,' as educators, we have no choice but to make interpretive decisions courageously and take a stand at every given moment in classroom. Just as Sartre managed to grow an optimistic and humanist message out of the smouldering ruins of postwar European philosophy and culture, so did Schwab blow a breath of optimism into the teacher's role.

Sartre and Schwab lived and worked in the 20th century, and both responded to the political and moral upheavals of their time. Their thought is still relevant and applicable today (for more on Schwab's enduring relevance, see Roby 2008; Ben-Peretz and Craig 2018). In the present era, the results of upheavals from their time remain to be finalized, or in any case have not received an adequate response. Indeed, in the postmodern era, there is probably no justification for universal curricula that pretend to impose 'objective truth' on masses of teachers and students in fixed and uniform ways. But even in this era, the teacher's classroom work is absolutely justified, if we conceive her as an artist, researcher, and subjective 
and creative interpreter of reality and the curriculum. The teacher's role is justified and essential as one who makes courageous decisions given the unique needs and predispositions of her students, and as one who copes with the necessary and never-ending challenge of freedom and responsibility.

\section{Practical Implications for the Classroom and School}

Having read Schwab through the lenses of Sartre's conceptual eyes of revived humanism, we find inspiration for a revision of teachers' image as active and conscious human subject, in an era where they are threatened to be conceived of as objects, or as technicians charged with implementing protocols.

The insights arising out of this synthesis of philosophical and pedagogical moves have practical implications for the entire education system, and the nature of teachers' work in classrooms. In rising to the challenges they face, and optimally and responsibly realizing their freedom, teachers require appropriate conditions; yet first, they themselves must approach their work properly. In what follows, I elaborate on several systemic conditions that expand teacher autonomy, and I conclude with two key teacher attributes that I deem essential in this regard.

\section{Systemic Conditions for Autonomous Teaching}

As we have seen, Schwab (1983) proposed complete decentralization of educational authorities through the structure of school curricular committees - an intriguing but controversial idea. Some (e.g., Tyler 1984) have criticized Schwab, claiming that the idea was not practicable under the current conditions of the US education system. Eisner $(1984,205)$ viewed Schwab's work as "a utopian model for the creation of curriculum policy." Schwab (1987) himself admitted later that his program for "curriculum chairmen" was a "dream program" for a "dream committee."

Nevertheless, even if we do not accept Schwab's proposal in full detail, it serves as an important reminder that the current centralized model familiar to us, as well as the extreme alternative of total classroom autonomy for every teacher, are not the only ones possible. Rather, expanding teachers' autonomy can mean partial expansion of the autonomy relegated to each teacher and as suggested above, ensuring that teachers are represented in high-level educational decision making. Partial expansion of classroom autonomy could mean, for example, that the centrally determined curricula would only provide general frameworks, within which each teacher could choose which contents to teach and how. It could also mean full responsibility on the part of teachers for evaluation processes.

Teacher representation is desirable not only in terms of ensuring freedom, but also as it would contribute to the success of educational reforms. Moreover, even if certain reforms declare the system's intention to expand teacher autonomy, their details conceal expressions of disrespect for teachers' professionalism and the way in which they compromise teachers' autonomy in practice (Milner 2013).

Even today, almost forty years after Practical 4 (Schwab 1983), the issue of teachers' autonomy remains high on the educational agenda. For it to be a real part of school life, 
greater collaboration is required. First, it is important to promote settings for knowledgesharing and mutual support amongst teachers, including colleagues working at the same school and/or teaching the same subject. Peer collaboration is essential in order to relieve the burden of tasks due to expanded teacher autonomy and to provide emotional support in dealing with freedom and responsibility. Digital medias have already been in use for a while, contributing to the range and speed of knowledge-sharing between teachers at different schools, including in remote geographical locations; I am confident that the boost in digital work amongst teachers that resulted from COVID-19 accelerates this stream of knowledge exchange.

Second, teachers acting autonomously must be backed by the school administration, which should enable them to implement their decisions and secure the students' cooperation. For example, if a teacher decides on a certain assessment method and therefore asks her students to complete assignments or meet certain requirements to succeed, as long as her decisions are pedagogically reasonable, the administration must respect them.

\section{The Autonomous Teacher: Commitment and Courage}

My argument for enlargement of teacher's freedom may meet the criticism that it is only suitable for the best teachers. Indeed, I have in mind inspiring examples of teachers who weave rich subject-matter expertise with sensitive appreciation for diverse student experiences and learning needs; Educators who are morally and socially committed to improve both their students and themselves, as well as the whole of society. I am aware, of course, that not all teachers meet these expectations, but I think that educational theory should indeed look at the right pedagogy and the right educational policy, aiming at the best professionals, and not compromising on a lesser level. Additionally, I argue that enlarging teacher's autonomy will improve the quality of teaching, both by encouraging the practitioners to excel, and by attracting intelligent and devoted young people to the field of education, as a profession that respects them as unique subjects.

However, even great teachers have conceptual and pedagogical blind spots, and some of us have ones that can profoundly hinder the learning and growth of our students. Having acknowledged that, it is important to emphasize that working autonomously does not entail working alone. On the contrary, Iargue that teachers whose agency is respected would comfortably seek for guidance and advise from colleagues, and would gladly share the fruits of their own work, thus improving the quality of teaching of the school's community.

I will now present two "personality requirements" that are essential for teachers to be able to meet the challenge of this role as portrayed by the synthesis of Sartre and Schwab. The autonomous teacher must be willing to work hard, and to be courageous enough to cope with the freedom and responsibility teaching entails. These two qualities - commitment and courage - characterize many teachers, but unfortunately not all. About the first, contrary to the assumption presented above that increased freedom would make teachers more motivated, in some cases expanded freedom is actually met with opposition from teachers, often on an organized level. One reason is that any reform effectively requires teachers to work more without being compensated for it. A teacher who plans the curriculum and evaluation processes herself needs to put up more hours. Some teachers dislike that, for obvious 
reasons, and teacher organizations encourage this approach, leading t $\mathrm{o}$ an organizational culture of avoiding any tasks related to expanded autonomy.

To change this culture, teachers' employment conditions must be improved. Nevertheless, this is not a panacea. As the motivational literature indicates (e.g., Pink 2009), when employees are engaged in personally meaningful work, they are willing to put up time and effort even with little external reward. I believe that teachers who experience greater autonomy first-hand will find the investment worth their while. Obviously, the students' cooperation and satisfaction are maximized when the teacher herself chooses the contents and methods, making the teaching experience more meaningful and rewarding.

Last but not least, courage is the order of the day. Another explanation for teachers' own opposition to greater autonomy is an experience akin to the Sartrean anxiety in the face of freedom. Cases of 'flight from freedom'-involving self-denial and the shirking of responsibility - occur when teachers, who are not privy to curricular decisions, are unwilling to represent them in front of their students, and hide behind 'higher authorities.' This situation is familiar to us all, when a teacher tells her class, for example, "I'm also bored by this material, but you have to study it because the Ministry of Education says so." Such statements only exacerbate the teachers' alienation from their work, as well as their self-denial. They also compromise the teachers' status, since they reduce the respect of students and their parents, thus undermining the teachers' demands for greater trust and autonomy, which are closely bound together.

Following Sartre's concept of authenticity, I argue that a partial solution for anxiety and for the resistance that comes with it, requires that we first of all frankly acknowledge this difficulty and appreciate the positive potential inherent in coping with it as a personal experience that gives meaning to life and work. We can find many positive examples for courage among teachers who undertake to lead reform processes in their schools, out of a sense of belonging and commitment, making the most out of the freedom that is their destiny and the responsibility that is their burden.

Indeed, teaching is not for cowards. Whoever chooses this profession must courageously face the freedom - and responsibility - involved. Further research should inquire into the optimal ways for teacher educators to prepare novice teachers for these aspects of their professional lives.

\section{References}

Aviram, A. 2010. Navigating through the Storm: Reinventing Education for Postmodern Democracies. Sense. Ben-Peretz, M., and C. J. Craig. 2018. Intergenerational impact of a curriculum enigma: The scholarly legacy of Joseph J. Schwab. Educational Studies 44 (4): 421-448.

Best, S., and D. Kellner. 2001. The postmodern adventure: Science, technology, and cultural studies at the third millennium. Guilford.

Bloom, A. 1987. The closing of the American mind. Simon \& Schuster.

Clarke, A., and G. Erickson. 2004. Self-study: The fifth commonplace. Australian Journal of Education 48 (2): 199-211.

Deci, E. L., and R. M. Ryan. 2012. Motivation, personality, and development within embedded social contexts: An overview of self-determination theory.

Dewey, J. 1966/1916. Democracy and education: An introduction to the philosophy of education. The Free Press.

Eisner, E. W. 1981. On the differences between Scientific and artistic approaches to qualitative research. Educational Researcher 10 (4): 5-9. 
Eisner, E. W. 1984. No easy answers: Joseph Schwab's contributions to curriculum. Curriculum Inquiry 14 (2): 201-210.

Fromm, E. 1941. Escape from freedom. Farrar \& Rinehart.

Gates, S. 2013, May 23. Teacher's resignation video: Ellie Rubenstein explains: "Everything I love about teaching is extinct". The Huffington Post. http://www.huffingtonpost.com/2013/05/23/teacher-resignation-video-ellie-rubenstein_n_3328117.html.

Giroux, H. 1993. Postmodernism as border pedagogy. In A postmodern reader, eds. J. P. Natoli, and L. Hutcheon, 452-489. SUNY Press.

Golomb, Y. 1988. Epilogue. In J. P. Sartre, Existentialism is a humanism (pp. 53-72). Mifras (Hebrew).

Guba, E. G., ed. 1990. The Paradigm Dialog. Sage.

Heineke, A. J., A. M. Ryan, and C. Tocci. 2015. Teaching, learning, and leading: Preparing teachers as educational policy actors. Journal of Teacher Education 66 (4): 382-394.

Hutchinson, D. A., and C. L. Clarke. 2019. Attending to the unfolding-ness: Exploring the complexities of curriculum making in teacher education. Landscapes, Edges, and Identity-Making. (Advances in Research on Teaching) 33: 17-35.

Kant, I. 1993/1785. Groundwork of the metaphysic of morals (3rd ed.) (J. W. Ellington, Trans.). Hackett.

Kuhn, T. 1962. The structure of scientific revolutions. University of Chicago Press.

Lyotard, J. F. 2006. The Lyotard reader and guide. Columbia University Press.

Luria, Y. 2002. Following the meaning of life: A philosophical journey. Maariv (Hebrew).

Milner, H. R. 2013. Policy reforms and deprofessionalization of teachers. National Education Policy Center.

Natoli, J. P., and L. Hutcheon, eds. 1993. A postmodern reader. SUNY Press.

Pink, D. H. 2009. Drive. Riverhead Hardcover.

Roby, T. W. 2008. How Joe Schwab thinks: A review of the practical 1 after 40 years. Journal of Curriculum theorizing 24 (1): 85-89.

Sartre, J. P. 1949/1947. What is Literature? (B. Frechtman, Trans.) Philosophical Library.

Sartre, J. P. 2007/1946. Existentialism is a humanism (C. Macomber, Trans.), Yale University Press.

Schwab, J. J. 1959. The" impossible" role of the teacher in progressive education. The School Review 67 (2): 139-159.

Schwab, J. J. 1969. The practical: A language for curriculum. School Review 78 (1): 1-23.

Schwab, J. J. 1971. The practical 2: Arts of eclectic. School Review 79 (4): 493-542.

Schwab, J. J. 1973. The practical 3: Translation into curriculum. School Review 81 (4): 501-522.

Schwab, J. J. 1983. The practical 4: Something for curriculum professors to do. Curriculum Inquiry 13 (3): 239-265.

Schwab, J. J. 1987. A reply to Charles Wegener. Curriculum Inquiry 17 (2): 229-233.

Shafir, S. 2020. The Real Failure-what could have been done with the hundreds of thousands. Haaretz, Tel-Aviv.

Tyler, R. 1984. Personal reflections on The Practical 4. Curriculum Inquiry 14 (1): 97-102.

Westbury, I. 2005. Reconsidering Schwab's 'Practicals': A response to Peter Hlebowitsh's 'Generational ideas in curriculum: A historical triangulation'. Curriculum Inquiry 35 (1): 89-101.

Publisher's Note Springer Nature remains neutral with regard to jurisdictional claims in published maps and institutional affiliations. 